Article

\title{
Krebs Cycle Intermediates Protective against Oxidative Stress by Modulating the Level of Reactive Oxygen Species in Neuronal HT22 Cells
}

\author{
Kenta Sawa ${ }^{1}$, Takumi Uematsu ${ }^{1}$, Yusuke Korenaga ${ }^{1}$, Ryuya Hirasawa ${ }^{1}$, Masatoshi Kikuchi ${ }^{1}$, \\ Kyohei Murata ${ }^{1}$, Jian Zhang ${ }^{1}$, Xiaoqing Gai ${ }^{1}$, Kazuichi Sakamoto ${ }^{2}$, Tomoyuki Koyama ${ }^{3}$ and \\ Takumi Satoh ${ }^{1, *}$ \\ 1 Department of Anti-Aging Food Research, School of Bioscience and Biotechnology, Tokyo University of \\ Technology, 1404-1 Katakura, Hachioji 192-0982, Japan; b01131253c@edu.teu.ac.jp (K.S.); \\ b01130437a@edu.teu.ac.jp (T.U.); b0113111b5@edu.teu.ac.jp (Y.K.); b01132115c@edu.teu.ac.jp (R.H.); \\ b01130888d@edu.teu.ac.jp (M.K.); b0113245f8@edu.teu.ac.jp (K.M.); 1099813793zj@gmail.com (J.Z.); \\ g11160462a@edu.teu.ac.jp (X.G.) \\ 2 Graduate School of Life and Environmental Sciences, University of Tsukuba, 1-1-1 Tennoudai, Tsukuba, \\ Ibaraki 305-8572, Japan; sakamoto@biol.tsukuba.ac.jp \\ 3 Laboratory of Nutraceuticals and Functional Foods Science, Graduate School of Marine Science and \\ Technology, Tokyo University of Marine Science and Technology, 4-5-7 Konan, Tokyo 108-8477, Japan; \\ tskoyama@kaiyodai.ac.jp \\ * Correspondence: satotkm@stf.teu.ac.jp; Tel.: +81-42-637-2485; Fax: +81-42-637-6314
}

Academic Editor: Debasis Mondal

Received: 18 January 2017; Accepted: 24 February 2017; Published: 16 March 2017

\begin{abstract}
Krebs cycle intermediates (KCIs) are reported to function as energy substrates in mitochondria and to exert antioxidants effects on the brain. The present study was designed to identify which KCIs are effective neuroprotective compounds against oxidative stress in neuronal cells. Here we found that pyruvate, oxaloacetate, and $\alpha$-ketoglutarate, but not lactate, citrate, iso-citrate, succinate, fumarate, or malate, protected HT22 cells against hydrogen peroxide-mediated toxicity. These three intermediates reduced the production of hydrogen peroxide-activated reactive oxygen species, measured in terms of $2^{\prime}, 7^{\prime}$-dichlorofluorescein diacetate fluorescence. In contrast, none of the KCIs—used at $1 \mathrm{mM}$ - protected against cell death induced by high concentrations of glutamate-another type of oxidative stress-induced neuronal cell death. Because these protective KCIs did not have any toxic effects (at least up to $10 \mathrm{mM}$ ), they have potential use for therapeutic intervention against chronic neurodegenerative diseases.
\end{abstract}

Keywords: oxaloacetic acid; alpha-ketoglutaric acid; pyruvic acid; reactive oxygen species; neuron

\section{Introduction}

The Krebs cycle is a series of enzymatic reactions that catalyze the aerobic metabolism of fuel molecules to carbon dioxide and water, thereby generating energy for the production of adenosine triphosphate molecules. Many types of fuel molecules can be drawn into and utilized by the cycle, including acetyl coenzyme A, derived from glycolysis or fatty acid oxidation. In eukaryotic cells, most of the enzymes catalyzing the reactions of the Krebs cycle are found in the mitochondrial matrixes [1]. The compounds involved in the cycle - termed Krebs cycle intermediates (KCIs)—function as energy donors and precursors for the synthesis of amino acids, lipids, and carbohydrates [2].

This aerobic metabolism may pervade every aspect of biology and medicine, because many papers published within the last 10 years suggest that KCIs regulate epigenetic processes and cellular signaling, possibly via protein binding [3]. KCIs activate specific signaling transduction pathways 
and exert various biological actions, such as neuroprotection, anti-inflammation, osteogenesis, and anti-aging [3]. For example, external supplementation with pyruvate (PA), oxaloacetate (OAA), $\alpha$-ketoglutarate (AKG), malic acid (MA) or fumarate (FA), but not lactic acid (LA), succinate (SA), citrate (CA) or iso-citrate (ICA) significantly extends the lifespan of Caenorhabditis elegans by activating various transcriptional factor(s)-dependent transcriptional pathways [4-6]. Although fragmental information about the physiological roles of KCIs in the brain is available, KCIs are also proposed as being cardioprotective agents against myocardical infarction [7]. FA and AKG have been proposed to protect cardiac muscles possibly through activating or inhibiting specific transcription factors, such as NF-E2 related factor 2 (NRF2) and hypoxia inducible factor (HIF-1), respectively. In neurons, PA prevents hydrogen peroxide $\left(\mathrm{H}_{2} \mathrm{O}_{2}\right)$-induced cell death [8,9], protects the brain against experimental stroke via an anti-inflammatory mechanism [10], and prevents the age-dependent cognitive deficits seen in a mouse model of Alzheimer's disease [11]. These protections are possibly due to its $\alpha$-ketoacid structure, which can directly react with $\mathrm{H}_{2} \mathrm{O}_{2}[8,9]$.

$\mathrm{H}_{2} \mathrm{O}_{2}$ is a stable, uncharged, and freely diffusible reactive oxygen species (ROS) with a putative second messenger role in intracellular and extracellular signaling mechanisms [12]. The generation of $\mathrm{H}_{2} \mathrm{O}_{2}$ is relatively high in the brain, partly because of the high activities of oxygen consumption and partly because of the high level of expression of monoamine oxidase in this tissue [13]. In pathological conditions such as ischemia-reperfusion and Alzheimer's disease, various cell types may produce large amounts of $\mathrm{H}_{2} \mathrm{O}_{2}$ [13]. In addition to enzymatic defense mainly mediated by various enzymes (i.e., glutathione (GSH) peroxidase, catalase, and peroxiredoxins), non-enzymatic mechanisms can also contribute to the cellular defense against $\mathrm{H}_{2} \mathrm{O}_{2}$-induced cytotoxicity [13]. For instance, PA is abundant in mammalian cells and has the property of non-enzymatically reacting with $\mathrm{H}_{2} \mathrm{O}_{2}[8,9]$. PA protects neurons against both exogenous and endogenous $\mathrm{H}_{2} \mathrm{O}_{2}$, and it also inhibits cell death mediated by $\mathrm{H}_{2} \mathrm{O}_{2}$ in neurons [8] and non-neuronal cells [9]. However, whether KCIs other than PA, $\mathrm{OAA}$, and AKG really elicit neuroprotection through a simple direct interaction with exogenous $\mathrm{H}_{2} \mathrm{O}_{2}$ at extracellular locations has not yet been fully clarified.

In this present study, we examined the neuroprotective effects of KCIs against two types of oxidative stress in neuronal HT22 cells and found that only three of them (PA, OAA, and AKG) - which have an $\alpha$-keto acid structure-had significant neuroprotective effects by modulating the levels of ROS in the cells. We found that the other KCIs were not protective, suggesting that these neuroprotective KCIs—used singly or as a cocktail—could be a potential food supplement for the purpose of preventing chronic neurodegeneration.

\section{Materials and Methods}

\subsection{Chemicals}

All KCIs (sodium salt), sodium glutamate (Glu), hydrogen peroxide $\left(\mathrm{H}_{2} \mathrm{O}_{2}\right)$, and 3-(4,5-dimethylthiazol-2-yl)-2,5-diphenyl tetrazolium bromide (MTT) were purchased from Wako Junyaku (Tokyo, Japan). Stock solutions of KCIs (100 or $1000 \mathrm{mM}$ ) were prepared in $\mathrm{Ca}^{2+}, \mathrm{Mg}^{2+}$-free phosphate-buffered saline (PBS(-), Invitrogen, Carlsbad, CA, USA). 2' , 7'-Dichlorodihydrofluorescin diacetate (DCFH-DA, Sigma-Aldrich, St. Louis, MO, USA) stock solution was prepared in $10 \mathrm{mM}$ dimethyl sulfoxide solution and used at $10 \mu \mathrm{M}$ in the culture medium.

\subsection{HT22 Cultures and MTT Assay}

HT22 hippocampal neuronal cells were cultured as described previously [14-16]. In HT22 cells, high concentrations (mM levels) of Glu can induce cell death by depleting intracellular GSH through inhibition of cystine influx, and relatively low concentrations ( $\mu \mathrm{M}$ levels) of $\mathrm{H}_{2} \mathrm{O}_{2}$ can induce cell death. Because HT22 cells do not have functional NMDA receptor proteins, they do not die due to excitotoxicity [14-16]. These cells were maintained in 10-cm dishes (Invitrogen, Carlsbad, CA, USA) containing $10 \mathrm{~mL}$ of Dulbecco's Modified Eagle medium supplemented with $10 \%(v / v)$ heat-inactivated 
$\left(56{ }^{\circ} \mathrm{C}, 30 \mathrm{~min}\right.$ ) fetal calf serum (Invitrogen). The cells were seeded into 24-well plates at a density of $4 \times 10^{4}$ cells $/ \mathrm{cm}^{2}$. When examining their effects on the $\mathrm{H}_{2} \mathrm{O}_{2}$ toxicity, we added KCIs to the cultures after a 24-h incubation. Sixty minutes later, 100, 200, or $500 \mu \mathrm{M} \mathrm{H}_{2} \mathrm{O}_{2}$ was added, and the cells were then incubated for an additional $24 \mathrm{~h}$. We set differential pre-incubation time $24 \mathrm{~h}$ and $1 \mathrm{~h}$ for Glu- and $\mathrm{H}_{2} \mathrm{O}_{2}$-toxicity, respectively. This was to stabilize the response to $\mathrm{H}_{2} \mathrm{O}_{2}$, and also because the Glu toxicity is completely inhibited by the long preincubation (over $5 \mathrm{~h}$ ) by an unknown mechanism [14-16]. When the effects of KCIs on oxidative Glu toxicity were examined, the cells were incubated for $1 \mathrm{~h}$ after having been seeded in wells of a 24-well plate, and the KCIs were then added to the cultures. Sixty minutes later, 5, 10, or $20 \mathrm{mM}$ Glu was added, and the cells were then incubated for an additional $24 \mathrm{~h}$. To evaluate survival of the HT22 cells, we performed the MTT assay [14-16].

\subsection{DCF Assay}

The extent of cellular oxidative stress was assessed by monitoring the formation of free-radical species by using DCFH-DA, as described elsewhere [17]. Cells were plated $24 \mathrm{~h}$ before initiation of the experiment at a density of 40,000 cells/well in 24-well plates. KCIs and $10 \mu \mathrm{M}$ DCFH-DA were added to the cells $30 \mathrm{~min}$ before the measurement. The plate was set into a Spark10M (Tecan Japan, Tokyo, Japan) under an atmosphere of $5 \% \mathrm{CO}_{2}$ and temperature of $37^{\circ} \mathrm{C}^{\circ} \mathrm{H}_{2} \mathrm{O}_{2}(200 \mu \mathrm{M})$ or vehicle was added to wells at $30 \mathrm{~min}$, and the cells were incubated further for $180 \mathrm{~min}$. DCF fluorescence was measured at a 485-nm excitation wavelength and 538-nm emission wavelength at 10-min intervals. Fluorescence values were expressed as a percentage of the value for the untreated control.

\subsection{Statistical Analysis}

Experiments presented herein were repeated at least three times, with each experiment performed in quadruplicate. Data were presented as the mean $\pm \mathrm{SD}$. The statistical significance of differences was examined by performing Student's $t$-test.

\section{Results}

\subsection{Neuroprotective Effect of $P A, O A A$, and AKG on HT22 Cells}

We used HT22 cells-a neuronal cell line derived from a mouse hippocampus-as a model for oxidative cell damage. Treatment of the cells with 100, 200, or $500 \mu \mathrm{M} \mathrm{H}_{2} \mathrm{O}_{2}$ (Figure 1A) or with 5, 10, or $20 \mathrm{mM} \mathrm{Glu}$ (Figure 1B) induced cell death by oxidative stress within $24 \mathrm{~h}$. Pre (1 h)-treatment of the cells with the KCIs at $1 \mathrm{mM}$ protected the cells from the toxic effects of $\mathrm{H}_{2} \mathrm{O}_{2}$ (Figure 1A), whereas these KCIs were not—or very little if they were-protective against Glu toxicity (Figure 1B). These KCIs were not toxic to HT22 cells up to $10 \mathrm{mM}$, but they caused a small but significant reduction in cell survival when used at 20-50 $\mathrm{mM}$ (Figure 2). These results suggest that PA, OAA, and AKG could protect neuronal cells against $\mathrm{H}_{2} \mathrm{O}_{2}$, but not against Glu.

\subsection{Regulation of ROS by $P A, O A A$, and $A K G$}

As the neuroprotective effects of the KCIs may have been due to the chemical structure of $\alpha$-keto acid by direct interaction with $\mathrm{H}_{2} \mathrm{O}_{2}$ inside the cells, we next examined whether the KCIs could reduce the level of ROS in HT22 cells (Figure 3). We quantified the levels of ROS with the ROS-sensitive fluorescent indicator DCFH-DA by use of a Spark 10M device (Tecan Japan, Tokyo, Japan). Based on the fluorescence activity, $\mathrm{H}_{2} \mathrm{O}_{2}(200 \mu \mathrm{M})$ increased the levels of ROS by 20-40-fold. ROS levels plateaued at 45-60 min of exposure. PA (Figure 3A) or OAA (Figure 3B) at 1, 2, or $10 \mathrm{mM}$, and 2 or $10 \mathrm{mM}$ AKG (Figure 3C) significantly lowered intracellular ROS formation; $1 \mathrm{mM}$ AKG did not reduce the ROS level. These results suggest that these KCIs used at low $\mathrm{mM}$ levels effectively reduced the ROS level in neural cells. 
A. $\mathrm{H}_{2} \mathrm{O}_{2}$
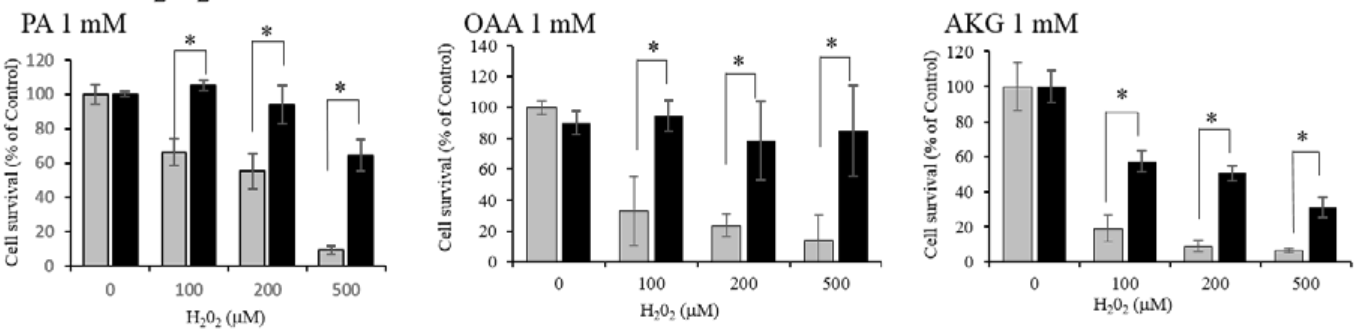

B. Glu
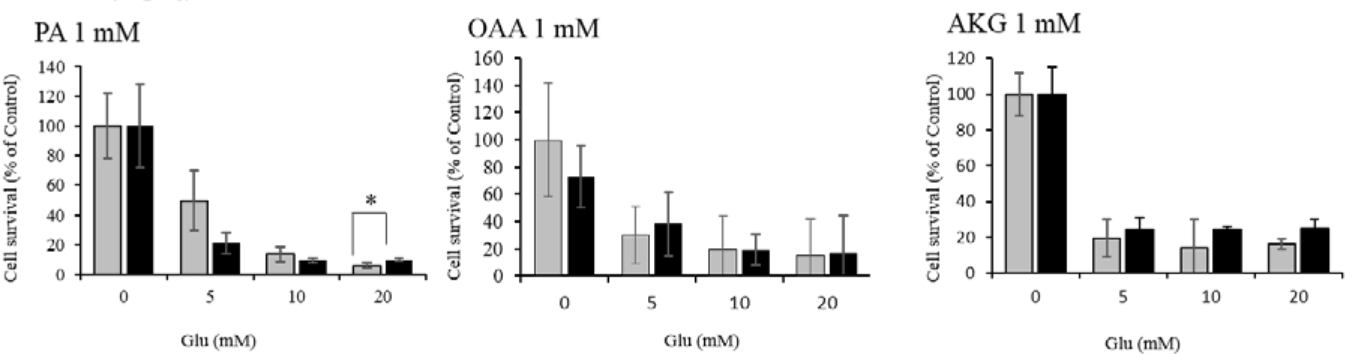

Figure 1. Protection of $\mathrm{HT} 22$ against (A) $\mathrm{H}_{2} \mathrm{O}_{2}$ and (B) Glu by pyruvate (PA), oxaloacetate (OAA), and $\alpha$-ketoglutarate (AKG). (A) Protective effects of $1 \mathrm{mM}$ PA, OAA, or AKG against various concentrations of $\mathrm{H}_{2} \mathrm{O}_{2}$. (B) No protective effect of $1 \mathrm{mM}$ PA, OAA, or AKG against high concentrations of Glu was found. White bars indicate $\mathrm{H}_{2} \mathrm{O}_{2}$ or Glu alone; and gray bars $\mathrm{H}_{2} \mathrm{O}_{2}+\mathrm{KCI}$ (PA, OAA, or AKG). Values, presented as a percentage of the control MTT (3-(4,5-dimethylthiazol-2-yl)-2,5-diphenyl tetrazolium bromide) value (obtained in the absence of glutamate), are given as the mean $\pm \operatorname{SD}(n=4)$. * significantly different $(p<0.05)$ from samples without a KCI. KCI: Krebs cycle intermediate.
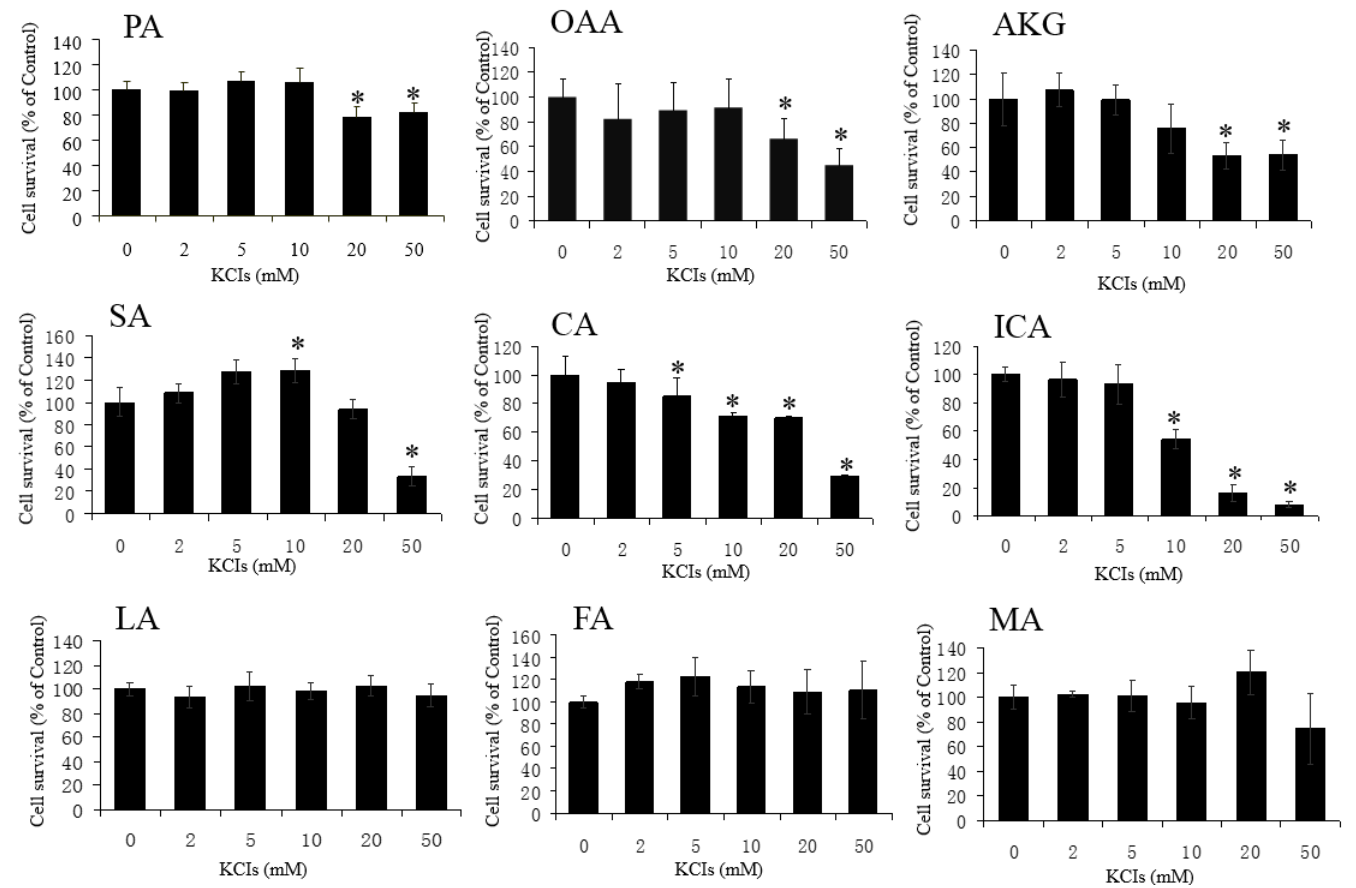

Figure 2. Toxic effects of KCIs by themselves. PA, OAA, AKG, succinate (SA), lactic acid (LA), fumarate (FA), and malic acid (MA) did not reduce cell survival up to $10 \mathrm{mM}$, whereas citrate (CA) and iso-citrate (ICA) reduced it when used at concentrations around 5-10 mM. Values, presented as a percentage of the control MTT value (obtained in the absence of glutamate), are given as the mean $\pm \operatorname{SD}(n=4)$. * significantly different $(p<0.05)$ from samples without a KCI. 

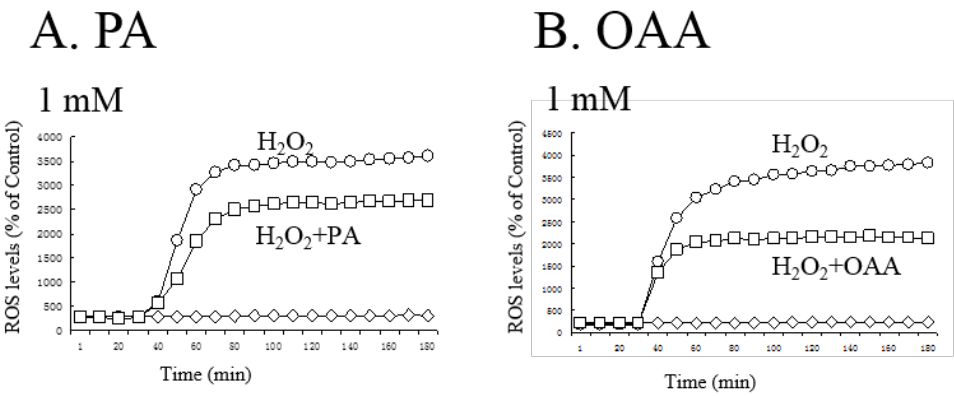

\section{AKG}
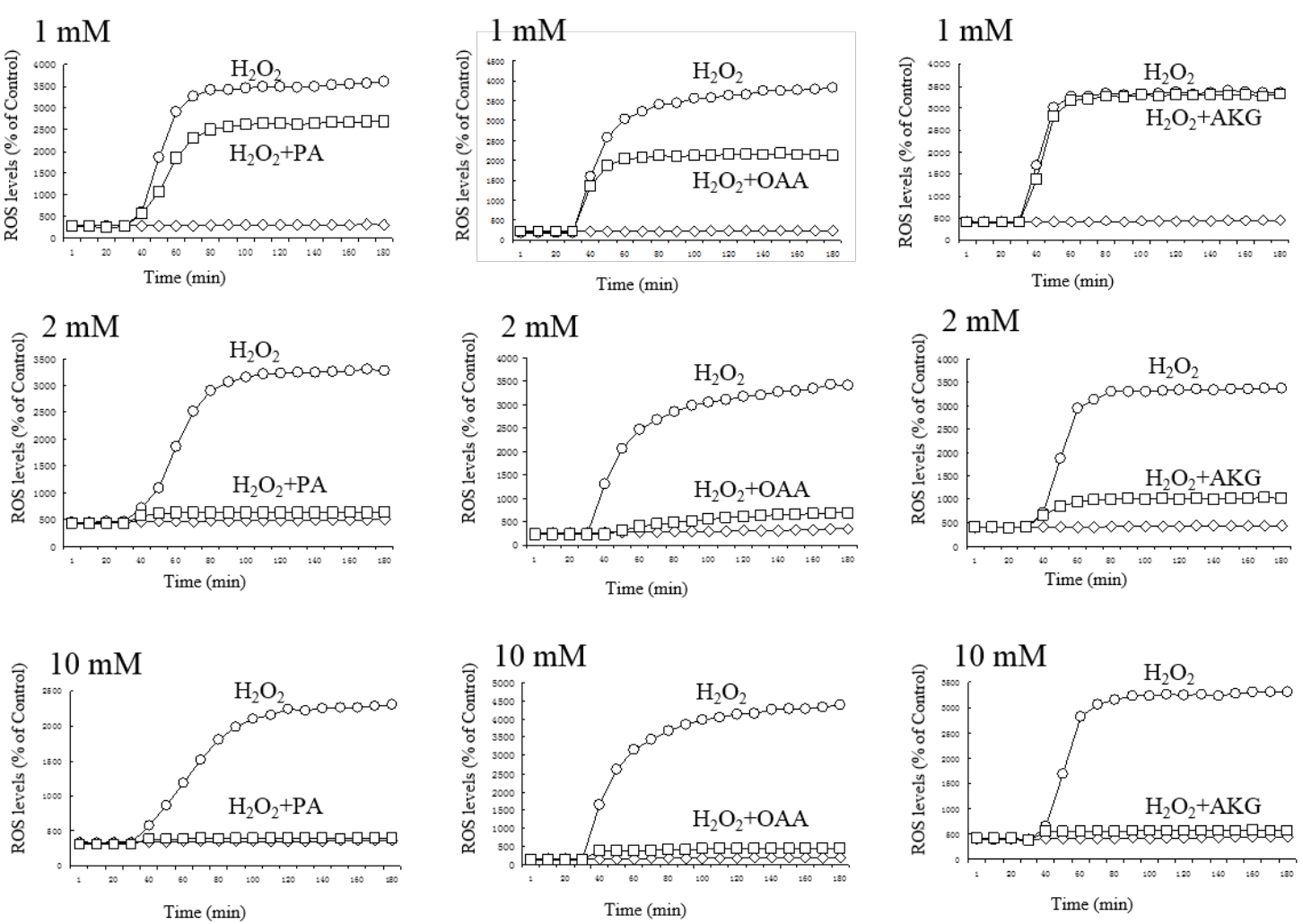

Figure 3. Modulation of reactive oxygen species (ROS) level by (A) PA, (B) OAA, or (C) AKG against $\mathrm{H}_{2} \mathrm{O}_{2}$-induced cytotoxicity. The measurement of the cells loaded with $10 \mu \mathrm{M}$ DCFH-DA $\left(2^{\prime}, 7^{\prime}\right.$-Dichlorodihydrofluorescin diacetate) for $30 \mathrm{~min}$ started at $0 \mathrm{~min}$, and DCF fluorescence levels are shown at 10-min intervals. Various concentrations $(1,2$, and $10 \mathrm{mM})$ of PA, OAA, or AKG were added to the cultures at the same time as DCFH-DA addition. $\mathrm{H}_{2} \mathrm{O}_{2}(200 \mu \mathrm{M})$ was added at $30 \mathrm{~min}$. Values are the means \pm SD from four experiments per group. Diamonds, control; circles, $\mathrm{H}_{2} \mathrm{O}_{2}$; squares, $\mathrm{H}_{2} \mathrm{O}_{2}+\mathrm{KCI}$. Note that the KCI alone groups were not shown in these graphs, because KCIs themselves did not affect ROS levels at any time point.

\subsection{No Protective Effects by LA, CA, ICA, SA, FA, and MA against $\mathrm{H}_{2} \mathrm{O}_{2}$}

Next, we assessed whether LA, CA, ICA, SA, FA, and MA could protect HT22 cells against $\mathrm{H}_{2} \mathrm{O}_{2}$, and found that these intermediates were not-or were very little if they were-protective against $\mathrm{H}_{2} \mathrm{O}_{2}(100,200$, and $500 \mu \mathrm{M})$-mediated cytotoxicity (Figure 4). Then, we examined whether these KCIs could protect the cells against Glu toxicity. Additionally, except for SA against $5 \mathrm{mM}$ Glu, these KCIs (at $1 \mathrm{mM}$ ) showed no protection against high concentrations (5, 10, and $20 \mathrm{mM}$ ) of Glu (Figure 5). These results indicate that LA, CA, ICA, SA, FA, and MA could not protect HT22 cells against oxidative stress. LA, SA, FA, and MA were not toxic to the cells up to $10 \mathrm{mM}$. By some unknown mechanism, CA and ICA gave toxic effects when tested around 5-10 mM (Figure 2). A high concentration of FA had an exceptional action on the cells, because $10 \mathrm{mM}$ FA gave significant protection against high concentrations of Glu (Figure 5). 

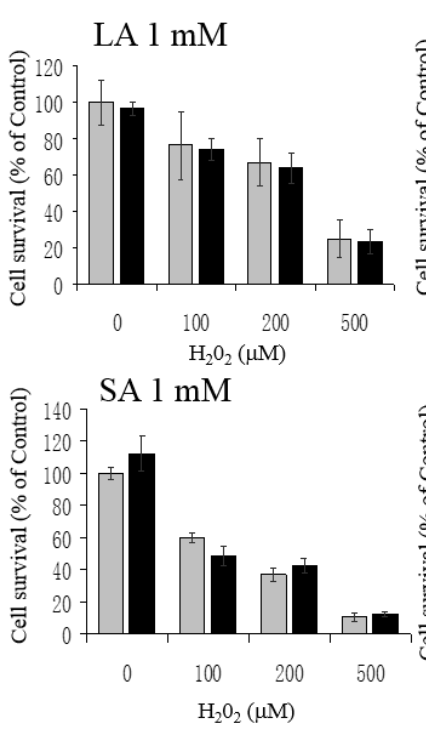

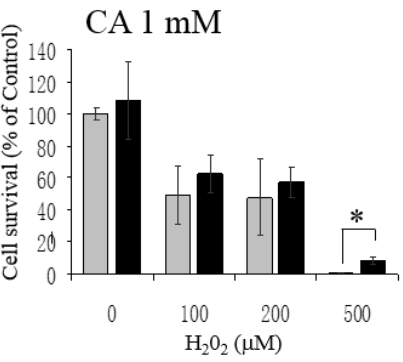

FA $1 \mathrm{mM}$

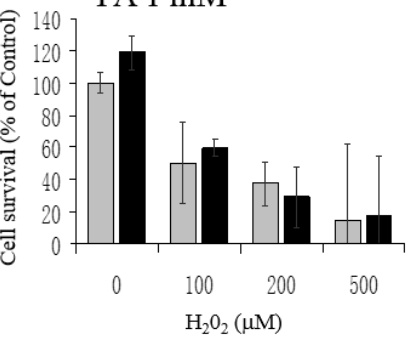

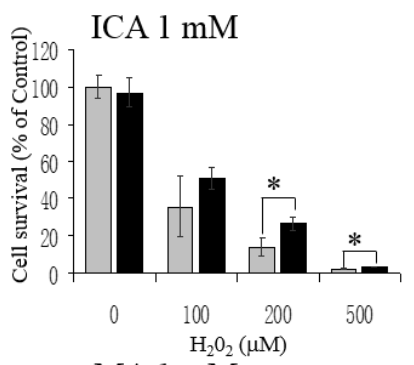

MA $1 \mathrm{mM}$

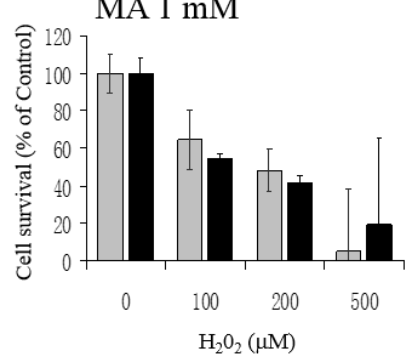

Figure 4. No protection of HT22 cells against $\mathrm{H}_{2} \mathrm{O}_{2}$ by the other KCIs at $1 \mathrm{mM}$. Neither LA, CA, ICA, SA, FA, nor MA protected the cells against $\mathrm{H}_{2} \mathrm{O}_{2}$-mediated cytotoxicity. White bars are $\mathrm{H}_{2} \mathrm{O}_{2}$ alone; and gray bars are $\mathrm{H}_{2} \mathrm{O}_{2}+\mathrm{KCI}$. Values, presented as a percentage of the control MTT value (obtained in the absence of glutamate), are given as the mean $\pm \operatorname{SD}(n=4) .{ }^{*}$ significantly different $(p<0.05)$ from samples without a KCI.
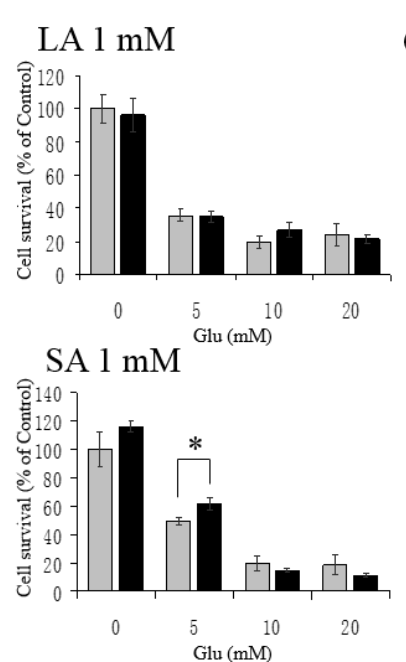

SA $10 \mathrm{mM}$

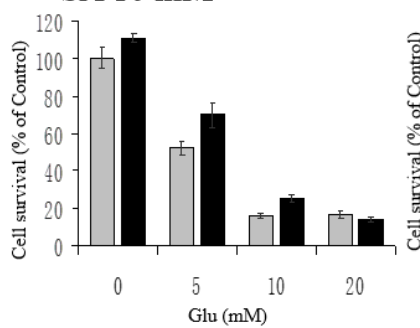

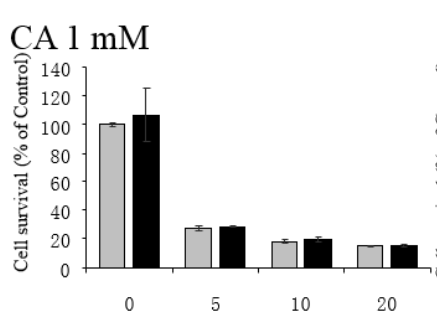
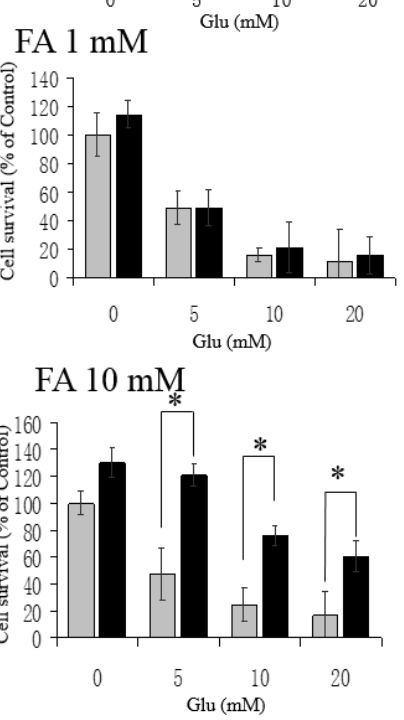
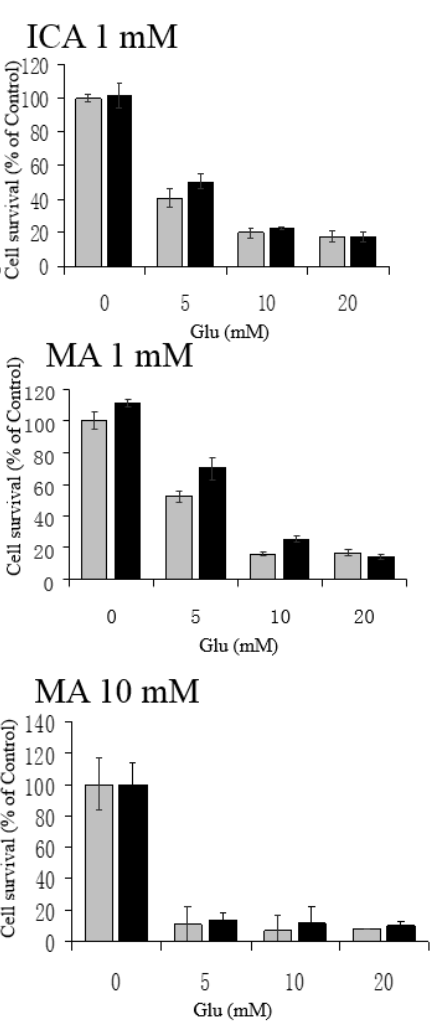

Figure 5. No protection of HT22 cells against Glu by the other KCIs at $1 \mathrm{mM}$. Neither LA, CA, ICA, SA, nor MA protected the cells against Glu used at 1 or $10 \mathrm{mM}$. FA at $10 \mathrm{mM}$ protected the cells against Glu, although $1 \mathrm{mM}$ FA did not. White bars indicate Glu alone, and gray bars Glu + KCI. Values, presented as a percentage of the control MTT value (obtained in the absence of glutamate), are given as the mean $+\mathrm{SD}(n=4)$. ${ }^{*}$ significantly different $(p<0.05)$ from samples without a KCI. 


\section{Discussion}

Here, we found that the $\alpha$-keto acid group-containing KCIs (PA, OAA, and AKG) could protect neurons against $\mathrm{H}_{2} \mathrm{O}_{2}$, possibly through direct interaction with $\mathrm{H}_{2} \mathrm{O}_{2}$, although we did not provide direct evidence for this chemical reaction itself. Because DCFH-DA is hydrolyzed by cytosolic esterase and is activated by ROS in the cytoplasm, the inhibition of ROS increase by PA, OAA, and AKG could be due to an $\mathrm{H}_{2} \mathrm{O}_{2}$-scavenging effect of them inside the cells. The conclusion of this study is illustrated in Figure 6A and B. PA, OAA, and AKG were neuroprotective, but not the other KCIs. For example, LA and MA - putative neuronal energy substrates that may produce protective KCIs through their metabolism [1,2]—did not protect the cells (Figures 4 and 5). AKG may have other protective effects than $\alpha$-keto acids such as PA and OAA. AKG at 1mM protected the cells against $\mathrm{H}_{2} \mathrm{O}_{2}$ (Figure 1) without causing a significant reduction in ROS levels (Figure 3). Because AKG is reported to activate the degradation of HIF- $1 \alpha$ subunit and reduce the expression of downstream enzymes [6,7], reduction of this pathway may have been involved in the protective effects of AKG. FA may be another exceptional KCI. FA at $10 \mathrm{mM}$ protected the cells against Glu-mediated cytotoxicity (Figure 5), although the other KCIs did not do so. Because FA is reported to activate the Nrf2 pathway and induce phase-2 enzymes [18], the activation of this pathway may have been involved in the FA-induced protection.

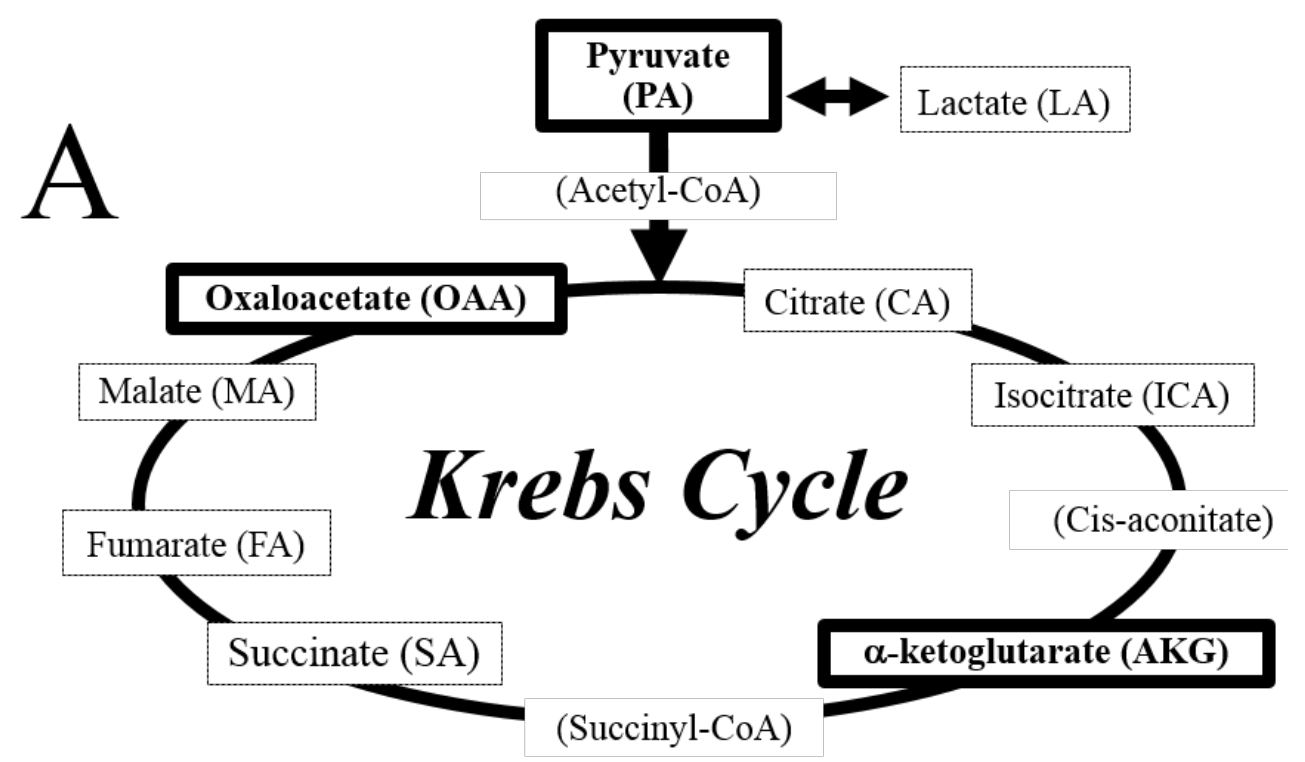

B

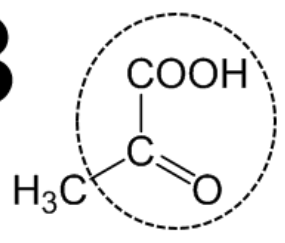

PA

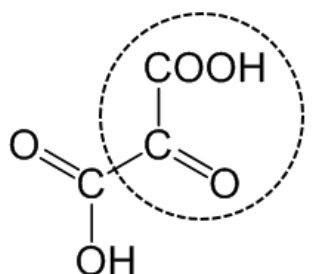

OAA

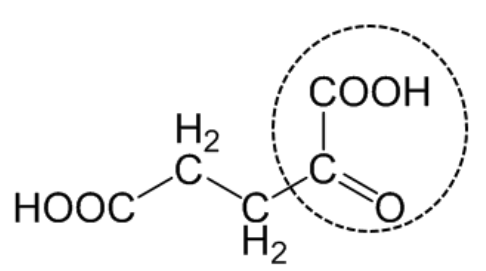

AKG

Figure 6. (A) Compounds involved in the Krebs cycle and (B) common chemical structure of neuroprotective KCIs (PA, OAA, and AKG). Note that PA, OAA, and AKG have the common chemical structure of the $\alpha$-keto acid group —indicated by the dotted circle-with which molecules can directly react with $\mathrm{H}_{2} \mathrm{O}_{2}$.

Interestingly, the protection afforded by PA, OAA, and AKG was totally different than that of NRF2 activators such as carnosic acid [19,20], zonarol [21,22], and tert-butyl hydroquinone [23]. 
These activators can protect cells against a high concentration of Glu, but not against $\mathrm{H}_{2} \mathrm{O}_{2}$. Nrf2 activators protect cells against high Glu concentrations by inhibiting the decrease in GSH by induction of Phase-2 enzymes, the action of which enhances the production of GSH [24-26]. The increase in GSH by NRF2 activators is not sufficient for protection against $\mathrm{H}_{2} \mathrm{O}_{2}$ [24-26].

\section{Conclusions}

This present study importantly suggests that there are 2 distinctive oxidative mechanisms: one induced by $\mathrm{H}_{2} \mathrm{O}_{2}$ and the other by Glu. $\alpha$-Ketoacid group-containing KCIs (PA, OAA, and AKG) protected the cells against the former but not against the latter, whereas Nrf2 activators act vice versa. The central nervous system is particularly vulnerable to oxidative damage due to its high energy expenditure and oxygen demand [24-26]. Elevated concentrations of free radicals and resultant oxidative damage, such as lipid peroxidation and protein carbonylation, have been repeatedly demonstrated in neurodegenerative disorders such as Alzheimer's disease, Parkinson's disease, and ischemic stroke [24-26]. Thus, PA, OAA, and AKG, being natural metabolic intermediates and energy substrates, exert antioxidant effects in the brain and other tissues susceptible to $\mathrm{H}_{2} \mathrm{O}_{2}$.

Acknowledgments: The authors thank Larry D. Frye for editorial help with the manuscript. This work was supported in part by grants-in-aid for scientific research (No. 22500282, 2011-2014 and No. 25350985, +32014-2017) from the JSPS.

Author Contributions: Kenta Sawa, Takumi Uematsu, Yusuke Korenaga, Ryuya Hirasawa, Masatoshi Kikuchi, Kyohei Murata, Jian Zhang, Xiaoqing Gai contributed the analysis. Kazuichi Sakamoto, Tomoyuki Koyama, and Takumi Satoh designed the experiments.

\section{Abbreviations}

AKG, $\alpha$-ketoglutarate; CA, citrate; Cont, control; DCFH-DA, 2' ,7'-Dichlorodihydrofluorescin diacetate; FA, fumarate; Glu, glutamate; GSH, glutathione; $\mathrm{H}_{2} \mathrm{O}_{2}$, hydrogen peroxide; HIF-1, hypoxia inducible factor; ICA, iso-citrate; KCI, Krebs cycle intermediate; LA, lactate; MA, malate; MTT, 3-(4,5-dimethylthiazol-2-yl)-2,5-diphenyl tetrazolium bromide; NRF2, NF-E2 related factor 2; OAA, oxaloacetate; PA, pyruvate; ROS, reactive oxygen species; PBS(-), $\mathrm{Ca}^{2+}, \mathrm{Mg}^{2+}$-free phosphate-buffered saline; $\mathrm{SA}$, succinate; $\mathrm{SD}$, standard deviation.

\section{References}

1. Krebs, H.A. The citric acid cycle and the Szent-Györgyi cycle in pigeon breast muscle. Biochem. J. 1940, 34, 775-779. [CrossRef] [PubMed]

2. Locasale, J.W.; Cantley, L.C. Metabolic flux and the regulation of mammalian cell growth. Cell Metab. 2011, 14, 443-451. [CrossRef] [PubMed]

3. De Berardinis, R.J.; Thompson, C.B. Cellular metabolism and disease: What do metabolic outliers teach us? Cell 2012, 148, 1132-1144. [CrossRef]

4. Edwards, C.B.; Copes, N.; Brito, A.G.; Canfield, J.; Bradshaw, P.C. Malate and fumarate extend lifespan in Caenorhabditis elegans. PLoS ONE 2013, 8, e58345. [CrossRef]

5. Williams, D.S.; Cash, A.; Hamadani, L.; Diemer, T. Oxaloacetate supplementation increases lifespan in Caenorhabditis elegans through an AMPK/FOXO-dependent pathway. Aging Cell 2009, 8, 765-768. [CrossRef] [PubMed]

6. Mishur, R.J.; Khan, M.; Munkácsy, E.; Sharma, L.; Bokov, A.; Beam, H.; Radetskaya, O.; Borror, M.; Lane, R.; Bai, Y.; et al. Mitochondrial metabolites extend lifespan. Aging Cell 2016, 15, 336-348. [CrossRef] [PubMed]

7. Czibik, G.; Steeples, V.; Yavari, A.; Ashrafian, H. Citric acid cycle intermediates in cardioprotection. Circ. Cardiovasc. Genet. 2014, 7, 711-719. [CrossRef] [PubMed]

8. Desagher, S.; Glowinski, J.; Prémont, J. Pyruvate protects neurons against hydrogen peroxide-induced toxicity. J. Neurosci. 1997, 17, 9060-9067. [PubMed]

9. Andrae, U.; Singh, J.; Ziegler, S.K. Pyruvate and related alpha keto acids protect mammalian cells in culture against hydrogen peroxide induced cytotoxicity. Toxicol. Lett. 1985, 28, 93-98. [CrossRef]

10. Wang, Q.; van Hoecke, M.; Tang, X.N.; Lee, H.; Zheng, Z.; Swanson, R.A.; Yenari, M.A. Pyruvate protects against experimental stroke via an anti-inflammatory mechanism. Neurobiol. Dis. 2009, 36, $223-231$. [CrossRef] [PubMed] 
11. Isopi, E.; Granzotto, A.; Corona, C.; Bomba, M.; Ciavardelli, D.; Curcio, M.; Canzoniero, L.M.; Navarra, R.; Lattanzio, R.; Piantelli, M.; et al. Pyruvate prevents the development of age-dependent cognitive deficits in a mouse model of Alzheimer's disease without reducing amyloid and tau pathology. Neurobiol. Dis. 2015, 81, 214-224. [CrossRef] [PubMed]

12. Reczek, C.R.; Chandel, N.S. ROS-dependent signal transduction. Curr. Opin. Cell Biol. 2015, 33, 8-13. [CrossRef]

13. Halliwell, B. Oxidative stress and neurodegeneration: Where are we now? J. Neurochem. 2006, 97, 1634-1658. [CrossRef] [PubMed]

14. Tamaki, Y.; Tabuchi, T.; Takahashi, T.; Kosaka, K.; Satoh, T. Activated glutathione metabolism participates in protective effects of carnosic acid against oxidative stress in neuronal HT22 cells. Planta Med. 2009, 76, 683-688. [CrossRef] [PubMed]

15. Satoh, T.; Rezaie, T.; Seki, M.; Sunico, C.R.; Tabuchi, T.; Kitagawa, T.; Yanagitai, M.; Senzaki, M.; Kosegawa, C.; Taira, H.; et al. Dual neuroprotective pathways of a pro-electrophilic compound via HSF-1-activated heat-shock proteins and Nrf2-activated phase 2 antioxidant response enzymes. J. Neurochem. 2011, 19, 569-578. [CrossRef] [PubMed]

16. Satoh, T.; Stalder, R.; McKercher, S.R.; Williamson, R.E.; Roth, G.P.; Lipton, S.A. Nrf2 and HSF-1 pathway activation via hydroquinone-based proelectrophilic small molecules is regulated by electrochemical oxidation potential. ASN Neuro 2015, 7. [CrossRef] [PubMed]

17. Wang, X.; Perez, E.; Liu, R.Y.; Yan, L.J.; Mallet, R.T.; Yang, S.H. Pyruvate protects mitochondria from oxidative stress in human neuroblastoma SK-N-SH cells. Brain Res. 2007, 1132, 1-9. [CrossRef] [PubMed]

18. Ashrafian, H.; Czibik, G.; Bellahcene, M.; Aksentijević, D.; Smith, A.C.; Mitchell, S.J.; Dodd, M.S.; Kirwan, J.; Byrne, J.J.; Ludwig, C.; et al. Fumarate is cardioprotective via activation of the Nrf2 antioxidant pathway. Cell Metab. 2012, 15, 361-371. [CrossRef] [PubMed]

19. Satoh, T.; Kosaka, K.; Itoh, K.; Kobayashi, A.; Yamamoto, M.; Shimojo, Y.; Kitajima, C.; Cui, J.; Kamins, J.; Okamoto, S.; et al. Carnosic acid, a catechol-type electrophilic compound, protects neurons both in vitro and in vivo through activation of the Keap1/Nrf2 pathway via S-alkylation of targeted cysteines on Keap1. J. Neurochem. 2008, 104, 1116-1131. [CrossRef] [PubMed]

20. Satoh, T.; Izumi, M.; Inukai, Y.; Tsutsumi, Y.; Nakayama, N.; Kosaka, K.; Shimojo, Y.; Kitajima, C.; Itoh, K.; Yokoi, T.; et al. Carnosic acid protects neuronal HT22 cells through activation of the antioxidant-responsive element in free carboxylic acid- and catechol hyroxyl moieties-dependent manners. Neurosci. Lett. 2008, 434, 260-265. [CrossRef] [PubMed]

21. Shimizu, H.; Koyama, T.; Yamada, S.; Lipton, S.A.; Satoh, T. Zonarol, a sesquiterpene from the brown algae Dictyopteris undulata, provides neuroprotection by activating the Nrf2/ARE pathway. Biochem. Biophys. Res. Commun. 2015, 457, 718-722. [CrossRef] [PubMed]

22. Yamada, S.; Koyama, T.; Noguchi, H.; Ueda, Y.; Kitsuyama, R.; Shimizu, H.; Tanimoto, A.; Wang, K.Y.; Nawata, A.; Nakayama, T.; et al. Marine hydroquinone zonarol prevents inflammation and apoptosis in dextran sulfate sodium-induced mice ulcerative colitis. PLoS ONE 2014, 9, e113509. [CrossRef] [PubMed]

23. Satoh, T.; Saitoh, S.; Hosaka, M.; Kosaka, K. Simple ortho- and para-hydroquinones as compounds neuroprotective against oxidative stress in a manner associated with specific transcriptional activation. Biochem. Biophys. Res. Commun. 2009, 379, 537-541. [CrossRef] [PubMed]

24. Satoh, T.; McKercher, S.R.; Lipton, S.A. The Nrf2-targetted antioxidant actions of pro-electrophilic drugs. Free Rad. Biol. Med. 2013, 65, 645-657. [CrossRef]

25. Lipton, S.A.; Rezaie, T.; Nutter, A.; Lopez, K.M.; Parker, J.; Kosaka, K.; Satoh, T.; McKercher, S.R.; Masliah, E.; Nakanishi, N. Therapeutic advantage of pro-electrophilic drugs to activate the Nrf2/ARE pathway in Alzheimer's disease models. Cell Death Dis. 2016, 7, e2499. [CrossRef] [PubMed]

26. Satoh, T.; Lipton, S.A. Redox regulation of neuronal survival mediated by electrophilic compounds. Trends Neurosci. 2007, 30, 37-45. [CrossRef] [PubMed]

(c) 2017 by the authors. Licensee MDPI, Basel, Switzerland. This article is an open access article distributed under the terms and conditions of the Creative Commons Attribution (CC BY) license (http:/ / creativecommons.org/licenses/by/4.0/). 